\title{
Taste, palatability and the control of appetite
}

\author{
Martin R. Yeomans \\ Experimental Psychology, University of Sussex, Brighton BN1 9QG, UK
}

The majority of research into the control of appetite has concentrated on the motivational constructs of hunger and satiety. The success of this approach is unquestionable, and we now know a great deal about the mechanisms underlying the initiation and cessation of eating. Yet it has proved more difficult to accommodate the influence of the sensory properties of foods into a framework of appetite control based around hunger and satiety alone. The present review examines the role of sensory factors, particularly taste and smell, in terms of their influence on food palatability, first by discussing the problems of defining and measuring palatability, and then by reviewing studies which have examined the effects of flavour manipulations on appetite. It is important at the outset to clarify the use of the words taste and flavour in this context. To the lay person, 'taste' itself is often used as an hedonic evaluation, for example when a food is described as 'tasting good'. A great deal of research into palatability has therefore used the word taste as synonymous with flavour. Technically, of course, these taste ratings are often based on flavour, that is they combine gustatory (taste) and olfactory (smell) components into a single percept, which is the flavour of the food. Thus, in the present review, ratings of the taste of complex foods are taken to be evaluations based on flavour, except where the stimuli tested only contained gustatory information.

\section{Defining palatability}

The problem of defining palatability has been the subject of a number of reviews (Young, 1967; Le Magnen, 1987; Cabanac, 1989; Berridge, 1996), yet there is still no single accepted definition (see Ramirez, 1990a,b). This lack of clarity arises, in part, from frequent circular use of the word palatability. If palatability is defined in terms of the ability of sensory factors to increase food intake, we cannot then observe an increase in intake and say this is a consequence of palatability. It has been suggested that an effective definition of palatability has to make specific reference either to some measured difference between foods which correspond with subsequent changes in eating (Kissileff, 1990), or to some underlying mechanism (Berridge, 1996). A second problem is in determining the precise relationship between the sensory properties of foods (chiefly taste, odour and texture) and food palatability. The use of the word palatability in some instances suggests this to be the hedonic evaluation of these sensory factors alone and, since these remain constant, palatability must therefore be an intrinsic and invariant property of the food. However, there is ample evidence that this is not the case. For example, when food is eaten the rated palatability of that food generally decreases (for example, see Rolls et al. 1984; Hetherington et al. 1989). Kissileff (1976) suggested a distinction between intrinsic palatability (which he saw as a property of the food) and reported palatability, which integrated the intrinsic palatability with other factors, including the consequences of associations between sensory properties and post-ingestive consequences as well as current motivational state. Other theorists dismiss the notion of intrinsic palatability completely, seeing palatability instead either as the sensory specific stimulation to eat ( $\mathrm{Le}$ Magnen, 1987), or the immediate effect of a particular food on ingestion (Booth, 1990). A third problem is the widespread tendency to use the word palatability to describe a food or diet without any attempt to provide data which support this claim. Ramirez $(1990 a, b)$ makes this point clearly when discussing studies on dietary-induced obesity in rats, where cafeteria diets are often described as highly palatable without any information to substantiate that claim other than the intake data, which (as discussed earlier) leads to a circular argument. The lack of a consistent definition for palatability has thus been a barrier to progress in this field (Booth, 1990; Rogers, 1990), and a widely accepted definition is needed to allow further advances. It is also essential that this is achieved while retaining the common-sense understanding of what palatability is (cf. Booth, 1990), since otherwise we are in danger of having a clearly defined psychological construct which bears little relation to our everyday experience of appetite. One aim of the present review is to examine the extent to which this goal has been achieved to date, and highlight those areas where current knowledge is still lacking.

\section{Measuring palatability effects in human subjects}

Once it is recognized that palatability is not a measurable component of foods, but is rather an hedonic evaluation of the food under particular circumstances, there comes the realization that palatability cannot be measured directly. Consequently, research into palatability in human subjects has made use of our ability to introspect. Thus, the most common 'measure' of palatability is some form of rating of the pleasure a subject experiences when eating a particular food under controlled conditions. Although the exact format of ratings of palatability has varied enormously, all such ratings require an evaluation on a prescribed scale of some hedonic attribute of the tested food. Some studies have used 
numerical scales with discrete labels at each point (e.g. the five-point scale used by Cabanac \& Duclaux, 1970a), while other researchers have used line-ratings or 'visual analogue scales' (for example, see Yeomans \& Wright, 1991). Ratings of this sort have been used to explore the effects of drugs on appetite (for example, see Blundell \& Rogers, 1980; Bertino et al. 1991; Yeomans \& Wright, 1991; Drewnowski et al. 1992), and to provide evidence for sensory specific satiety (for example, see Rolls et al. 1984; Hetherington et al. 1989). These scales have also been used to explore the detailed relationship between nutrient concentration and liking for sweet (for example, see Cabanac \& Duclaux, 1970a; Moskowitz et al. 1976) and salty tastes (for example, see Cabanac \& Duclaux, 1970b; Looy et al. 1992), and modelling of the relationship between these ratings and varying levels of sugar and fat have resulted in important claims about the nature of eating disorders (for example, see Drewnowski et al. 1985; Drewnowski, 1991). The widespread use of these scales has thus had a major impact on appetite research, and a detailed analysis of their use is beyond the scope of the present review. These ratings do need to be interpreted with some caution, however, since even small changes in the question posed to subjects can effect the outcome. For example, Rogers \& Blundell (1990) reported differences in the change in rated pleasantness across a meal depending on whether subjects rated the pleasantness of the taste of a food or the pleasantness of eating that food. Even more dramatically, if subjects are asked to make separate ratings of taste pleasantness and palatability, a proportion of subjects report a marked decrease in pleasantness but no change in palatability between the start and end of a meal (Yeomans, 1996). Despite these shortcomings, the use of various forms of hedonic ratings to index at some level food palatability remains one of the few options available to explore hedonic influences on eating, and it has been argued that inclusion of these measures at least allows some evaluation of the causal nature of palatability effects (Kissileff, 1990).

\section{Palatability and models of appetite control}

Although some attempt to incorporate a role for sensory evaluation has been made in most models of appetite, many models have (arguably) underplayed the importance of these influences. The simplest approach viewed palatability as little more than a reflection of the role of sensory factors in the decision whether or not to start to eat a particular food item, rather than how much of that item to eat (for a discussion of these ideas, see Rozin, 1982). At the opposite extreme, palatability (seen as synonymous with the pleasure of eating) has been viewed as an 'excellent index of satiety and hunger motivation' (Cabanac, 1989). However, attempts to model normal meal patterns using homeostatic constructs of hunger and satiety alone have failed (see McFarland, 1971). Only when these models included some mechanism which acted to maintain eating once it had started, did a pattern of eating akin to meal-taking emerge (for example, see Booth et al. 1976; Booth, 1978). These descriptive models make few suggestions about how such a mechanism may operate. However, more recently, theorists have suggested that the actions of palatability may be mediated through positive-feedback (for example, see Blundell \& Rogers,
1991), or orosensory reward (Berridge, 1996). These models offer a cogent way of conceptualizing how palatability might influence appetite. The second aim of the present review is to make some evaluation of the relative merits of these different ways of conceptualizing appetite control.

\section{The appetizer effect}

Implicit in models of appetite which invoke orosensory reward as an influence on eating is the notion that appetite can be increased by eating, an idea first raised by Le Magnen (1985). In the present review an appetizer effect is defined as an increase in appetite which can be attributed to the sensory properties (particularly taste and/or smell) of the eaten food(s), and so offers a behavioural description of the stimulation of appetite which can then be used to explore underlying mechanisms. The appetizer effect is not synonymous with palatability. Although palatability may normally be the variable most likely to induce an appetizer effect, the same behavioural effect (enhanced appetite) may conceivably be produced by manipulations which do not alter palatability.

There are several reasons why the appetizer concept may not have been widely explored in relation to controls of appetite. First, any short-term enhancement of food intake described by the appetizer effect may be compensated for by later reductions in intake, and thus the appetizer effect may have a broadly neutral effect on total energy balance when measured over periods longer than individual meals. Indeed, the fact that large-scale changes in eating patterns by rats, either by limiting access to food (for example, see Collier, 1983 ) or using conditioned cues to initiate feeding (Weingarten, 1984), has little effect on energy intake has led to an energy-driven approach to understanding appetite control, which sees long-term intake measurement and energy regulation as the primary concerns (for example, see Friedman, 1991). The frequent attribution of the increase in incidence of human obesity to overconsumption of palatable foods (for example, see Drewnowski \& Popkin, 1997) questions this approach. Second, many models of appetite fail to suggest any physiological mechanism(s) which might underlie the appetizer effect. However, as discussed previously, there is increasing reference to orosensory reward processes in appetite control (for example, see Berridge, 1996), and these could be seen as the physiological mechanisms which underlie the appetizer effect, and indeed some of the research reviewed in the present paper supports this claim.

\section{Measuring the effect of manipulated palatability on appetite}

The simplest way of assessing the role of palatability in appetite control is to manipulate the sensory properties of a food without altering nutrient content, and then measuring the effects of this manipulation on subsequent eating behaviour. If the effects of palatability manipulated in this way were the consequences of some underlying control of appetite, then it follows that sensory manipulations which change palatability to the same extent should have equivalent effects on eating. 


\section{Studies using preferred foods}

The most common experimental approach to the study of manipulated palatability on appetite is to make use of natural variation in human flavour preferences. Typically, experiments contrast eating with preferred and non-preferred versions of a similar food, and draw some inference about the role of palatability from differences in measured eating behaviour. These types of study have variously shown increased meal size, meal duration, eating rate and hunger ratings as palatability increased (Hill, 1974; Bellisle \& Le Magnen, 1980; Bellisle et al. 1984; Hill et al. 1984; Guy-Grand et al. 1989, 1994; Spiegel et al. 1989). However, in all these studies the test foods do not differ on palatability alone, and although it is clear that palatability is the most likely causal explanation for these changes in eating, nutritional influences cannot be excluded completely in these studies.

\section{Manipulating flavour using olfactory stimuli}

Flavourings (most commonly in the form of herbs and spices) are an important element of most cuisines, yet generally these compounds have little effect on the nutritional quality of foods. For as long as man has cooked, he has modified the flavour of foods using these compounds. Thus, flavouring of this sort offers an established way of manipulating the overall flavour of a food without altering macronutrient content. However, relatively few studies have used this approach. The first study used cumin (Cuminum cyminum) to modify the flavour of a palatable yoghurt (Bobroff \& Kissileff, 1986) This manipulation reduced the rated pleasantness of the food, and reduced intake. Bobroff \& Kissileff (1986) contrasted this with previous reports using less-specific flavour manipulations, and suggested that any flavour manipulation which increased rated palatability by one point on a seven-point scale (or roughly ten points on a 100-point line rating) will increase intake of that food by approximately $100 \mathrm{~g}$. Results of studies since that report, in general, agree with this contention, including studies in this laboratory using the addition of oregano (Origanum vulgare)

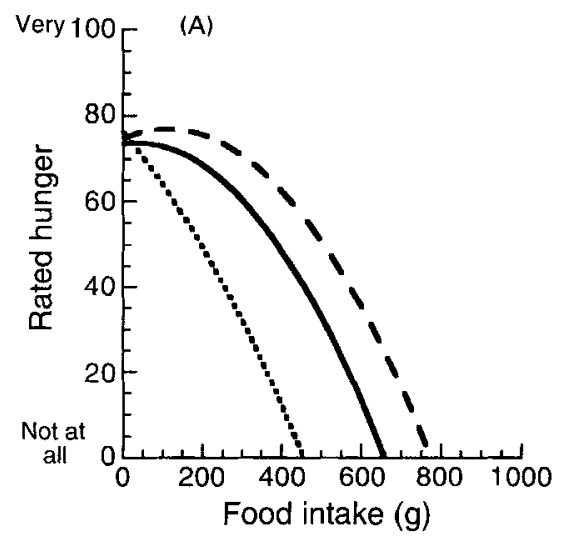

to alter the palatability of a tomato sauce served with pasta (Yeomans, 1996; Yeomans et al. 1997).

Although the demonstration of a consistent relationship between flavour manipulation and food intake is a useful starting point for understanding the role of palatability in appetite control, there is still some danger of circularity in this argument. In order to explore this relationship in more detail, researchers have analysed actual eating behaviour under these conditions. Building on previous work using less-controlled palatability manipulations (Bellisle \& Le Magnen, 1980; Bellisle et al. 1984), Bobroff \& Kissileff (1986) found that subjects ate slower overall in their lower-palatability cumin condition, especially at the start of the meal. We also found an effect of palatability in our studies with oregano (Yeomans, 1996; Yeomans et al. 1997). Following on from the pioneering work of Hill et al. (1984), we have also explored how palatability manipulations alter the experience of appetite during a meal. Initial studies divided each meal into 2 min eating episodes (bouts), with appetite ratings made in each inter-bout interval (Yeomans, 1996). When the change in rated hunger across the meal was modelled mathematically, the resulting best-fit quadratic functions also varied with palatability. However, only one component of these best-fit functions was affected, the linear coefficient, which was more positive (i.e. representing a greater tendency for hunger to increase) in the more palatable condition (Fig. 1). This effect was seen both with men and women, although it was more evident in women in that study. When the strength of the food flavour was increased further, these behavioural manifestations of an increased appetite disappeared. We have since replicated the effect of increasing palatability in this way using a more sophisticated methodology (Yeomans et al. 1997), whereby intake is monitored constantly using a hidden digital balance, and interruptions in eating are made after every $50 \mathrm{~g}$ consumed (measured by a computer connected to the balance). The effect of the palatability manipulation appears to be robust, and is independent of the constraints on eating which are seen in these studies. These results are consistent with a causal sequence of behaviour in which the manipulation of palatability (hedonic evaluation of a food) leads to a stimulation

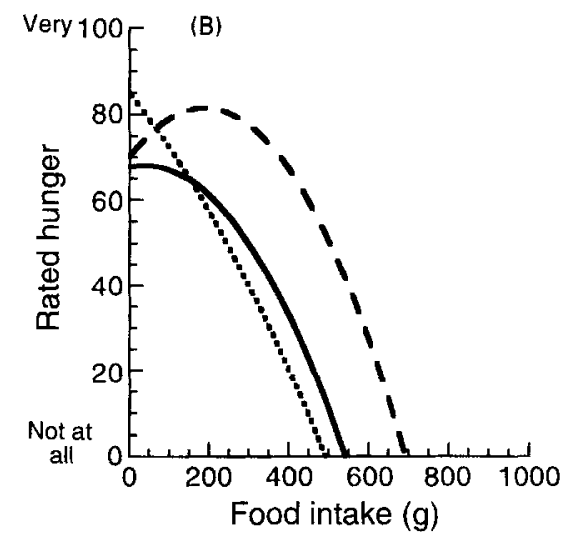

Fig. 1. Best-fit quadratic functions relating rated hunger $v$. food eaten for men $(A)$ and women $(B)$ eating three versions of pasta in a tomato sauce: with no added oregano (bland; ——), with $4 \%$ oregano (Oreganum vulgare) $/ \mathrm{kg}$ (palatable; — - ) and with $8 \mathrm{~g}$ oregano/kg (too strong; …). (Adapted from Yeomans, 1996.) 
of appetite (the appetizer effect), which in turn increases food consumption.

\section{Manipulating flavour using basic taste stimuli}

It is a basic premise of food science that the four main taste receptors have important influences on eating. At one level this influence appears to be dependent on innate responses to these tastes, with sweet and salty tastes tending to be liked by most individuals, whereas bitter and sour tend to be disliked (for review, see Logue, 1991). The area of liking for sweet tastes has been studied extensively by Cabanac and his colleagues (see Cabanac, 1989), but sweet tastes have not been used to modify flavour in studies akin to those described earlier on palatability, probably because of the potential confound with the nutrient content of sugar, as well as concerns about direct effects of non-nutrient sweeteners on appetite (for example, see Rogers et al. 1988; Rolls et al. 1990). Bitter tastants have been used to reduce palatability of foods, and these manipulations reduce food intake in a reliable manner (for example, see Nisbett, 1968). One problem with this approach is that the manipulation always reduces palatability. We have recently started to explore the effects of manipulating another basic tastant $(\mathrm{NaCl})$ where it should be possible to both increase and decrease palatability depending on salt concentration. Although salty tastes are generally disliked when experienced in isolation (for example, see Cabanac \& Duclaux, 1970b), salty tastes are liked in the context of actual food stimuli (see Beauchamp et al. 1991). Thus, the manipulation of salt concentration in the context of a savoury food offered a way of testing whether the appetizer effect seen with olfactory manipulations is also exhibited with a basic tastant. In our laboratory, male volunteers were asked to evaluate a series of samples of pasta in a tomato sauce, with salt concentration in the sauce varied. In subsequent lunchtime tests, intake and changes in rated appetite were assessed for this food when it contained each subject's most preferred level of salt, as well as two additional levels representing the concentration above and below the preferred level at which point food pleasantness was rated as neutral. In line with our previous work on flavour manipulation, overall intake was again a function of rated pleasantness, with intake

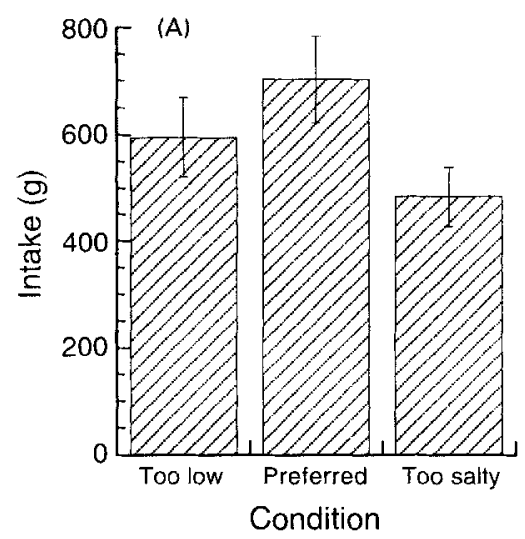

greater when the food had the preferred salt conditions than in the other two conditions (Fig. 2). Detailed analysis of changes in rated appetite within meals demonstrated a clear relationship between pleasantness ratings and the appetizer effect, indexed as the linear coefficient of the quadratic function relating hunger $v$. intake. This linear function did not differ from neutral (zero) when subjects ate food with a salt content slightly above or below their preferred salt content, but was positive when subjects ate their preferred food. Consequently, rated appetite only increased in the early stages of eating the food with the preferred level of salt. Thus, as with more complex flavour manipulations, adjusting the concentration of a basic tastant (salt) had predictable effects on appetite.

Another interesting feature of the effects of varying salt content on appetite was an apparent increase in the rate of satiation as the salt level increased (see Fig. 2), indexed both by a tendency to eat less and for a larger quadratic coefficient relating rated hunger $v$. intake. It is possible that the higher salt content induced a state of osmotic satiety (Mook \& Yoo, 1991). Osmotic satiety has also been used to explain why higher salt intake at breakfast reduced intake at lunch (Gray, 1997). It is worth noting that subjects were not allowed to drink water while eating in the lunch study, or between breakfast and lunch in the preload study, and it is likely that normal drinking would reduce this effect.

The conclusion from this section of the present review is that manipulations of flavour, whether achieved by the additions of basic tastants or olfactory stimuli, have predictable effects on appetite which are consistent with Le Magnen's (1987) contention that meal size is a product of the dual actions of positive reinforcement and satiation. They also highlight the advantage of detailed analyses of eating in dissociating these different motivational controls, thereby generating a framework which can be used to explore the physiological controls of appetite.

\section{Palatability and the physiological control of appetite}

The similarity in the behavioural consequence of altering rated food pleasantness regardless of whether this was achieved by various manipulations of taste and olfaction,

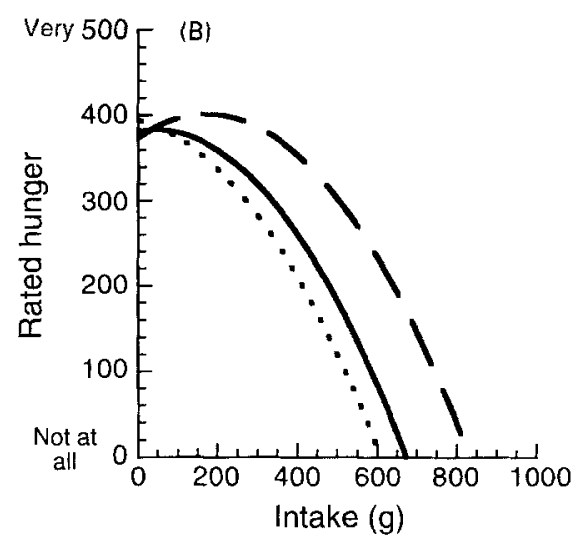

Fig. 2. Total food intake (A) and best-fit quadratic functions relating rated hunger $v$. food eaten, $(B)$ for men eating pasta in a tomato sauce with three levels of added salt: with too little salt (too low; - - ), with the ideal amount of salt (preferred; $-{ }_{-}$) and with too much salt (too salty; .....). Values are means with their standard errors represented by vertical bars. (Yeomans, unpublished results.) 
suggests that these effects may be generated by a single underlying mechanism. However, when compared with factors associated with the start of feeding (hunger) and those involved in the termination of feeding (satiation and satiety), where there is now considerable understanding of the underlying control mechanisms, the physiological basis of palatability effects remains relatively unexplored. An exception has been the study of the role of the opioid peptides in food intake control. The idea that these neurochemicals may be involved in the mechanisms underlying the influence of palatability originated in the animal literature (for reviews, see Reid, 1985; Cooper et al. 1988). The main evidence to support that case was first that blocking opioid receptors using selective opioid receptor antagonists caused a much greater reduction in intake of sweet and salty solutions in rats than it did for less-preferred solutions such as water (for example, see Cooper, 1983; Cooper \& Gilbert, 1984). Thus, opioid blockade appeared to reduce the orosensory reward value of food (see Cooper et al. 1988). That this effect was a consequence of the taste of these solutions, as opposed to some post-ingestive effect, was demonstrated in shamdrinking studies, where opioid blockade was shown to greatly reduce sham-drinking of sweetened solutions (Kirkham \& Cooper, 1988). Thus, it was suggested that opioids are normally released in the brain in response to taste cues, and the consequence of opioid release is to maintain ingestion. The opioid-palatability hypothesis has since been explored further in human subjects. The rated pleasantness of sweet tastes (Fantino et al. 1986; Melchior et al. 1987; Drewnowski et al. 1989), and complex flavours of normal foods (Bertino et al. 1991; Yeomans \& Wright, 1991; Yeomans \& Gray, 1996; but see Hetherington et al. 1991) are reduced by drugs which block opioid receptors. Opioid blockade has also been shown to block the appetizer effect (Yeomans \& Gray, 1997). Subjects who received naltrexone (an opioid-receptor antagonist) orally before lunch ate less, and reported lower pleasantness of the foods eaten, than when they had received a placebo or no drug treatment. When the relationship between rated hunger and intake was modelled as a quadratic function, only the linear component of this function was affected by opioid antagonism. This function was positive in both placebo and no-drug conditions, representing a tendency for an increase in rated hunger. However, this function was negative after naltrexone treatment. Since our previous work (Yeomans, 1996) implicated the linear function as an expression of the influence of palatability, these findings suggest that the modulatory role of opioids on appetite is achieved through altered palatability.

Although opioid blockade is at present the only neurochemical manipulation which reliably alters palatability, other neurochemical systems will certainly have a role, and future research may well lead to new findings. One area where there is a clear likelihood of further advances in our understanding is that of the role of the neurotransmitter $\gamma$-aminobutyric acid. One subcomponent of $\gamma$-aminobutyric acid receptors is the binding site in the central nervous system for the benzodiazepines (see Richards et al. 1991). As with opioids, there is compelling data in the animal literature that drugs which act on these benzodiazepine receptors alter palatability (see Cooper, 1991; Cooper \& Higgs, 1994;
Berridge \& Pecina, 1995). Recently, in the first reported study of the effects of a benzodiazepine-receptor agonist on human appetite, Haney et al. (1997) reported a substantial increase in food intake (by $35 \%$ ) after administration of the commonly-used benzodiazepine-receptor drug alprazolam to human volunteers. This is consistent with the benzodiazepine-palatability hypothesis (Berridge \& Pecina, 1995), although since no measures of flavour preference or relative food preference were made in that study, further research is needed to verify this.

\section{Conclusions}

The first aim of the present review. was to try and clarify the definition of palatability. The studies reviewed here clearly support the idea that palatability is the hedonic evaluation of sensory factors such as taste and smell of a food. The fact that palatability can be altered by a pharmacological manipulation which failed to alter the perceived sensations of sweetness or saltiness of the rated foods (Yeomans \& Wright, 1991), clearly demonstrates the dissociation between sensation and hedonic evaluation. Thus, the findings reviewed here are most consistent with Le Magnen's (1987) views on palatability, and suggest that palatability should be defined as the hedonic evaluation of orosensory food cues under standardized conditions.

The second aim was to explore the interrelationship between sensation and appetite. The similarity in effect on behaviour of a wide variety of manipulations of palatability demonstrates that these effects are consistent and robust. The review also highlights the value of detailed analyses of behaviour, and suggest a framework for future research. Manipulations of palatability will be most informative when achieved by the use of flavour manipulations which allow both increases and decreases in palatability in the absence of changes in nutrient content. This both allows for dissociation of sensory effects and possible confounding effects of the flavour manipulation (e.g. the possibility of osmotic satiety in our studies on manipulation of salt content), while guarding against confounds based on immediate nutritional effects or possible changes in palatability brought about by association of flavours with post-ingestive consequences. The benefits of this work in terms of our increased understanding of the physiological mechanisms underlying the effects of palatability are beginning to be realized, but this is an area where there is much work still to be done.

\section{References}

Beauchamp GK, Bertino M \& Engelman K (1991) Human salt appetite. In Chemical Senses, vol. 4, Appetite and Nutrition, pp. 85-107 [MI Friedman, MG Tordoff and MR Kare, editors]. New York, NY: Dekker.

Bellisle F \& Le Magnen J (1980) The analysis of human feeding patterns: the Edogram. Appetite 1, 141-150.

Bellisle F, Lucas F, Amrani R \& Le Magnen J (1984) Deprivation, palatability and the micro-structure of meals in human subjects. Appetite 5, 85-94.

Berridge KC (1996) Food reward: brain substrates of wanting and liking. Neuroscience and Biobehavioral Reviews 20, 1-25. 
Berridge KC \& Pecina S (1995) Benzodiazepines, appetite and taste palatability. Neuroscience and Biobehavioral Reviews 19, 121-131.

Bertino M, Beauchamp GK \& Engelman K (1991) Naltrexone, an opioid blocker, alters taste perception and nutrient intake in humans. American Journal of Physiology 261, R59-R63.

Blundell JE \& Rogers P (1980) Effects of anorexic drugs on food intake, food selection and preferences and hunger motivation and subjective experiences. Appetite 1, 151-165.

Blundell JE \& Rogers PJ (1991) Hunger, hedonics, and the control of satiation and satiety. In Chemical Senses, vol. 4, Appetite and Nutrition, pp. 127-148 [MI Friedman, MG Tordoff and MR Kare, editors]. New York, NY: Dekker.

Bobroff EM \& Kissileff $H$ (1986) Effects of changes in palatability on food intake and the cumulative food intake curve of man. Appetite 7, 85-96.

Booth DA (editor) (1978) Prediction of feeding behaviour from energy flows in the rat. In Hunger Models - Computable Theory of Feeding Control, pp. 227-278. London: Academic Press.

Booth DA (1990) How not to think about immediate dietary and post-ingestional influences on appetites and satieties. Appetite 14, 171-179.

Booth DA, Toates FM \& Platt SV (1976) Control system for hunger and its implications in animals and man. In Hunger: Basic Mechanisms and Clinical Implications, pp. 127-143 [D Novin, W Wyricka and G Bray, editors]. New York, NY: Raven Press.

Cabanac M (1989) Palatability of food and the ponderostat. Annals of the New York Academy of Sciences 575, 340-352.

Cabanac M \& Duclaux R (1970a) Obesity: absence of satiety aversion to sucrose. Science 168, 496-497.

Cabanac M \& Duclaux R (1970b) Specificity of internal signals in producing satiety for taste stimuli. Nature 229, 125-127.

Collier GH (1983) Life in a closed economy: the ecology of learning and motivation. In Advances in the Analysis of Behavior, vol, 3, Biological Factors in Learning, pp. 223-274 [MD Zeiler and P Harzem, editors]. Chichester: Wiley.

Cooper SJ (1983) Suppression of saccharin-induced drinking in the nondeprived rat by low dose diazepam treatment. Pharmacology Biochemistry and Behavior 18, 825-827.

Cooper SJ (1991) Ingestional responses following benzodiazepine receptor ligands, selective 5-HT-1A agonists and selective 5-HT-3 receptor antagonists. In 5-HT-1A Agonists, 5-HT-3 Antagonists and Benzodiazepines: their Comparative Behavioural Pharmacology, pp. 233-265 [RJ Rodgers and SJ Cooper, editors]. Chichester: Wiley.

Cooper SJ \& Gilbert DB (1984) Naloxone suppresses fluid consumption in tests of choice between sodium chloride solutions and water in male and female water-deprived rats. Psychopharmacology 84, 362-367.

Cooper SJ \& Higgs S (1994) Neuropharmacology of appetite and taste preferences. In Appetite: Neural and Behavioural Bases, pp. 212-243 [CR Legg and DA Booth, editors]. Oxford: Oxford University Press.

Cooper SJ, Jackson A, Kirkham TC \& Turkish S (1988) Endorphins, opiates and food intake. In Endorphins, Opiates and Behavioural Processes, pp. 143-186 [RJ Rodgers and SJ Cooper, editors]. Chichester: John Wiley.

Drewnowski A (1991) Fat and sugar: sensory and hedonic aspects of sweet, high-fat foods. In Chemical Senses, vol. 4, Appetite and Nutrition, pp. 69-83 [MI Friedman, MG Tordoff and MR Kare, editors]. New York, NY: Dekker.

Drewnowski A, Brunzell JD, Sande K, Iverius PH \& Greenwood MRC (1985) Sweet tooth reconsidered: taste responsiveness in obesity. Physiology and Behavior 35, 617-622.
Drewnowski A, Gosnell B, Krahn DD \& Canum K (1989) Sensory preferences for sugar and fat: evidence for opioid involvement. Appetite 12, 206.

Drewnowski A, Krahn DD, Demitrack MA, Nairn K \& Gosnell BA (1992) Taste responses and preferences for sweet high-fat foods: evidence for opioid involvement. Physiology and Behavior 51, 371-379.

Drewnowski A \& Popkin BM (1997) The nutrition transition: new trends in the global diet. Nutrition Reviews 55, 31-43.

Fantino M, Hosotte J \& Apfelbaum M (1986) An opioid antagonist, naltrexone, reduces preference for sucrose in humans. American Journal of Physiology 251, R91-R96.

Friedman MI (1991) Metabolic control of calorie intake. In Chemical Senses, vol. 4, Appetite and Nutrition, pp. 19-38 [MI Friedman, MG Tordoff and MR Kare, editors]. New York, NY: Marcel Dekker.

Gray RW (1997) Hedonic factors in food choice. DPhil Thesis, University of Sussex.

Guy-Grand B, Lehner V \& Doassans M (1989) Effects of palatability and meal type on food intake in normal weight males. Appetite 12, 213-214.

Guy-Grand B, Lehnert V, Doassans M \& Bellisle F (1994) Type of test-meal affects palatability and eating style in humans. Appetite $22,125-134$

Haney M, Comer SD, Fischman MW \& Foltin RW (1997) Alprazolam increases food intake in humans. Psychopharmacology 132, 311-314.

Hetherington M, Rolls BJ \& Burley VJ (1989) The time course of sensory-specific satiety. Appetite 12, 57-68.

Hetherington MM, Vervaet N, Blass E \& Rolls BJ (1991) Failure of naltrexone to affect the pleasantness or intake of food. Pharmacology Biochemistry and Behavior 40, 185-190.

Hill AJ, Magson LD \& Blundell JE (1984) Hunger and palatability: tracking ratings of subjective experience before, during and after the consumption of preferred and less preferred food. Appetite 5 , 361-371.

Hill SW (1974) Eating responses of humans during dinner meals. Journal of Comparative and Physiological Psychology 86, 652-657.

Kirkham TC \& Cooper SJ (1988) Attenuation of sham feeding by naloxone is stereospecific: evidence for opioid mediation of orosensory reward. Physiology and Behavior 43, 845-847.

Kissileff HR (1976) Palatability. In International Encyclopedia of Psychiatry, Psychology, Psychoanalysis and Neurology, vol. 10, p. 172. New York, NY: Academic Press.

Kissileff HR (1990) Some suggestions on dealing with palatability - response to Ramirez. Appetite 14, 162-166.

Le Magnen J (1985) Hunger. Cambridge: Cambridge University Press.

Le Magnen J (1987) Palatability: concept, terminology and mechanisms. In Eating Habits: Food, Physiology and Learned Behaviour, pp. 131-154 [RA Boakes, DA Popplewell and MJ Burton, editors]. Chichester: Wiley.

Logue AW (1991) The Psychology of Eating and Drinking. New York, NY: Freeman.

Looy H, Callaghan S \& Weingarten HP (1992) Hedonic response of sucrose likers and dislikers to other gustatory stimuli. Physiology and Behavior 52, 219-225.

McFarland DJ (1971) Feedback Mechanisms in Animal Behaviour. London: Academic Press.

Melchior JC, Rozen R, Fantino M \& Apfelbaum MU (1987) Negative alliesthesia induced by a low-dose of naltrexone in normal human subjects. International Journal of Obesity 11, 60.

Mook DG \& Yoo DK (1991) Inhibition of sham feeding by hyperosmotic gastric infusions in rat. Psychobiology 19, 359-364. 
Moskowitz HR, Kumraiah V, Sharma KN, Jacobs HL \& Sharma SD (1976) Effects of hunger, satiety and glucose load upon taste intensity and taste hedonics. Physiology and Behavior 16, $471-475$.

Nisbett RE (1968) Determinants of food intake in obesity. Science 159, 1254-1255.

Ramirez I (1990a) What do we mean when we say 'palatable food'? Appetite 14, 159-161.

Ramirez I (1990b) What do we mean when we say 'palatable food'? Commentary. Appetite 14, 180.

Reid LD (1985) Endogenous opioid peptides and regulation of feeding and drinking. American Journal of Clinical Nutrition $\mathbf{4 2}$, 1099-1132.

Richards G, Schoch P \& Jenck F (1991) Benzodiazepine receptors and their ligands. In 5-HT-1A Agonists, 5-HT-3 Antagonists and Benzodiazepines: their Comparative Behavioural Pharmacology, pp. 1-30 [RJ Rodgers and SJ Cooper, editors]. Chichester: Wiley.

Rogers PJ (1990) Why a palatability construct is needed. Appetite 14, 167-170.

Rogers PJ \& Blundell JE (1990) Psychobiological bases of food choice. British Nutrition Foundation Nutrition Bulletin 15 , 31-39.

Rogers PJ, Carlyle JA, Hill AJ \& Blundell JE (1988) Uncoupling sweet taste and calories: comparison of the effects of glucose and three high intensity sweeteners on hunger and food intake. Physiology and Behavior 43, 547-552.

Rolls BJ, Kim S \& Fedoroff IC (1990) Effects of drinks sweetened with sucrose or aspartame on hunger, thirst and food intake in men. Physiology and Behavior 48, 19-26.
Rolls BJ, Van Duijenvoorde PM \& Rolls ET (1984) Pleasantness changes and food intake in a varied four-course meal. Appetite 5 , 337-348.

Rozin P (1982) Human food selection: the interaction of biology, culture and individual experience. In The Psychobiology of Human Food Selection, pp. 225-254 [LM Barker, editor]. Westport, CT: AVI Publishing.

Spiegel TA, Shrager EE \& Stellar E (1989) Responses of lean and obese subjects to preloads, deprivation and palatability. Appetite 13, 46-69.

Weingarten HP (1984) Meal initiation controlled by learned cues: basic behavioral properties. Appetite 5, 147-158.

Yeomans MR (1996) Palatability and the microstructure of eating in humans: the appetiser effect. Appetite 26, 119-133.

Yeomans MR \& Gray RW (1996) Selective effects of naltrexone on food pleasantness and intake. Physiology and Behavior $\mathbf{6 0}$, 439-446.

Yeomans MR \& Gray RW (1997) Effects of naltrexone on food intake and changes in subjective appetite during eating: evidence for opioid involvement in the appetiser effect. Physiology and Behavior 62, 15-21.

Yeomans MR, Gray RW, Mitchell CJ \& True S (1997) Independent effects of palatability and within-meal pauses on intake and subjective appetite in human volunteers. Appetite 29, 61-76.

Yeomans MR \& Wright P (1991) Lower pleasantness of palatable foods in nalmefene-treated human volunteers. Appetite 16, 249-259.

Young PT (1967) Palatability: the hedonic response to foodstuffs. In Handbook of Physiology, section 6, Alimentary Canal, vol. 1, pp. 353-366 [CF Code, editor]. Washington, DC: American Physiology Society. 